\title{
ANÁLISE COMPARATIVA DOS ARTIGOS 472 DO CPC/73 E 506 DO CPC/2015: CONVITE A UM DEBATE
}

\author{
Claudio Cesar Carvalho* \\ Luiz Fernando Bellinetti***
}

Resumo: Tem-se por escopo fazer apontamentos sugestivos acerca da alteração redacional entre os artigos 472 do Código de Processo Civil de 1973 (CPC/73) e com o art. 506 do atual $(\mathrm{CPC} / 15)$ e suas respectivas implicações jurídicas. A problemática nasce do silêncio doutrinário e jurisprudencial que pode ter consequências graves. Procedeu-se a uma análise redacional comparativa a sugestivos institutos jurídicos, partindo-se de uma pesquisa bibliográfica, pelo método dedutivo, colhendo-se os principais referenciais doutrinários ao intuito de comparar aqueles dispositivos legais e concluir pela importância de que o tema seja urgentemente enfrentado pela doutrina.

Palavras-chave: Comparativo; análise; alteração legal; art. 472 do CPC/73; art. 506 do $\mathrm{CPC} / 15$.

\section{COMPARATIVE ANALYSIS BETWEEN ARTICLE 472 OF CPC/73 AND ARTICLE 506 OF THE CURRENT CPC/2015: CALL FOR A DEBATE}

\begin{abstract}
This essay aims to make suggestive observations about the wording amendment between art. 472 of the Brazilian Code of Civil Procedure, 1973 (CPC/73) and art. 506, current code (CPC/15), in addition to their respective legal implication. Regarding this matter, the lack of doctrine and jurisprudence may have serious consequences. Based on a literature search, a comparative analysis of wordings to the investigation of suggestive body of laws was carried out in this study applying the deductive approach. The main doctrinal references were gathered in order to compare those legal frameworks emphasizing the importance and urgency of developing doctrine.
\end{abstract}

Keywords: Comparative; analysis; legal amendments; art. 472, CPC/73; art. 506, CPC/15.

\section{INTRODUÇÃO}

Busca-se, após uma análise doutrinária, estudar de forma comparativa os artigos 472 do Código de Processo Civil de 1973 (que aqui se chamará CPC/73) e o art. 506 do Código de Processo Civil de 2015 (CPC), fazendo apontamentos sugestivos de suas implicações, inclusive no que diz respeito às ações coletivas.

\footnotetext{
* Mestrando em Direito Negocial (UEL). Detém Especializações e Licenciatura Plena. Advogado, Professor e Palestrante, nas linhas de Processo Civil e Acesso à Justiça. E-mail: contato@ claudiocesarcarvalho.com.br.

${ }^{* *}$ Professor Associado da UEL. Doutor em Direito (PUC-SP). Foi Procurador de Justiça no Estado do Paraná. Email: luizbel@uol.com.br.
} 
Estas, próprias dos interesses transindividuais, ganharam alento com o avanço e a promoção veloz da tecnologia. A rapidez no fluxo de informações, os casos comparativos, a intensificação dos negócios e das relações jurídicas, passaram a demandar uma urgente resposta pelo Direito.

A doutrina ganhou papel importante na construção dos esclarecimentos que pudessem direcionar e resolver os casos complexos, envolventes das questões próprias da coisa julgada na esfera coletiva e, assim, servindo de subsídio para as reformas legislativas e evolução jurisprudencial.

O fato é que o referido tema proposto é objeto de discussão há décadas no direito pátrio, sem uma definição uníssona. O artigo 472 do Código de Processo Civil de 1973, antes de sua revogação pelo Código de Processo Civil de 2015, intensificado por legislações esparsas, tais como o Código de Defesa do Consumidor (CDC; mais precisamente em seu art. 103), foram alvo de uma série de formulações teóricas, por diversos autores.

Fato maior, talvez esteja no reconhecimento de que as causas individuais parecem acrescer de interesses coletivos, especialmente por terceiros que de alguma forma se beneficiam ou queiram se beneficiar de uma ação alheia. As demandas coletivas e o tema das ações massificadas são exemplos disso.

Está-se sob um tempo de preocupação institucional, em primeiro plano, pois a segurança jurídica, a noção do devido processo legal, do contraditório e da ampla defesa são institutos que estão intimamente ligados ao tema da coisa julgada, portanto, carecendo de atenção especial, em face de sua importância.

Neste passo, percebeu-se quando da reforma do Código Processual Civil, através do art. 506, esta preocupação. O dispositivo que sobreveio em reforma ao art. 472 do CPC/73 ganhou alteração redacional significativa e, pensa-se, que ao invés de se por fim aos debates doutrinários, estes irão alargar. É preciso que a doutrina debata, pois o instituto da coisa julgada demanda atenção.

Buscando-se uma releitura de ambos dispositivos, o revogado e o atual, num aspecto comparativo, e tecendo algumas conclusões, parte-se de uma pesquisa metodológica, pautada em um conteúdo exploratório. Utilizou-se do método dedutivo para, através do levantamento de dados via pesquisa bibliográfica, especialmente em periódicos e livros atinentes ao tema da coisa julgada, numa base axiológica de consideração dos princípios e valores fundamentais do 
ordenamento, visando ao final expor uma conclusão que seja formadora e acadêmica aos profissionais do Direito.

\section{AS REDAÇÕES DOS ARTIGOS 472 DO CPC/73 E 506 DO CPC/2015 E DADOS DOUTRINÁRIOS}

A mudança redacional entre o revogado artigo 472 do CPC/73 para com seu atual correspondente art. 506 do CPC/15 (nCPC) parece ser significativa não apenas do ponto de vista formal, mas material. Mas sem ainda adentrar nas questões técnicas, em simples sede comparativa, vejam-se os textos:

\begin{tabular}{|l|l|}
\hline CPC-73, art. 472: A sentença faz coisa & CPC-15, art. 506: A sentença faz coisa \\
julgada às partes entre as quais é dada, & julgada às partes entre as quais é dada, não \\
não beneficiando, nem prejudicando & prejudicando terceiros. \\
terceiros. Nas causas relativas ao estado & \\
de pessoa, se houverem sido citados no & \\
processo, em litisconsórcio necessário, & \\
todos os interessados, a sentença produz & \\
coisa julgada em relação a terceiros. &
\end{tabular}

No caput, percebe-se a exclusão da expressão "não beneficiando" terceiros e a parte final, quando diz que "nas causas relativas ao estado de pessoa, se houverem sido citados no processo, em litisconsórcio necessário, todos os interessados, a sentença produz coisa julgada em relação a terceiros" (WAMBIER, 2016, p . 406).

Ao que se aparenta, o intuito do legislador em excluir uma série de palavras constantes do antigo texto foi além de uma esfera de economia de expressões, mas sim no sentido de reformular a concepção jurídica de determinados institutos. Se realmente foi esta a intenção, ou até mesmo se não, deve haver a preocupação da doutrina para com a alteração redacional, especialmente porque esta passa pela análise da qualidade dos efeitos da coisa julgada, a qual possui íntima relação com os interesses transindividuais e, sobretudo, com as ações coletivas. 
Neste sentido, há quem já indique a necessidade de revisão dos institutos jurídicos relacionados às disposições do art. 506 do CPC. É, por exemplo, a proposta de Marcelo Abelha, com nossos grifos:

Não obstante o CPC ao mencionar no art. 506 que a sentença faz coisa julgada às partes, entre as quais é dada, não prejudicando terceiros, segundo, pois em absoluto, a doutrina de Enrico Tullio Liebman, somos obrigados a nos render aos apontamentos certeiros de Barbosa Moreira, que corajosamente retrucou o mestre e, além disso, apresentou solução mais convincente para o problema, mas que que ao nosso ver, sob o imperativo constitucional atual, precisa ser revisitada $(2016, \mathrm{p}$. 701).

No entanto, e nesta linha "corajosa", conforme afirmou o autor, percebe-se que a doutrina - numa plataforma geral - tem mantido um grave silêncio acerca do comparativo entre o art. 472 do CPC/73 e o art. 506 do CPC/15. Poucos, mas não todos, arriscam-se a tratar efetivamente das duas disposições, acabando por tratar um importante instituto sem a devida atenção às questões fundamentais do CPC/15 e tudo aquilo que o novo Código “inaugurou”. Os reflexos de uma eventual má compreensão podem ser drásticos.

Especificamente com relação à alteração redacional, Antônio do Passo Cabral afirma por ser elogiável, contudo, o próprio autor vê que há uma questão discutível, já que a interpretação lógica do dispositivo pode estar em confronto com a doutrina predominante sobre o assunto:

\footnotetext{
Na redação do art. 472 do CPC de 1973, a coisa julgada "não beneficiava" nem "prejudicava" terceiros. A nova redação da lei processual excluiu a expressão 'beneficiar', e agora a coisa julgada não atinge terceiros para prejudica-los, podendo, todavia, os atingir para beneficiá-los. A solução é elogiável ao prever a possibilidade de extensão da coisa julgada a terceiros para beneficiá-los; mas é criticável porque vai na contramão da tendência mundial ao não permitir, em nenhuma hipótese, que a coisa julgada possa atingir terceiros mesmo para prejudica-los. (...) A regra legal do novo CPC é boa porque, afinal, se é o contraditório o vetor para definir a limitação objetiva da coisa julgada, seria natural imaginar que um terceiro que não participou do processo não deve ser atingido pela proibição decorrente da coisa julgada (...). Não obstante, se o conteúdo (estabilizado pela coisa julgada for favorável ao terceiro, este pode se valer da coisa julgada e pretender que a questão se mantenha indiscutível em seu favor. Trata-se da coisa julgada in utilibus para terceiro. A mudança em relação em relação ao texto do CPC de 1973 é muito positiva (in TALAMINI, p. 811-812).
}

Tereza Arruda Alvim Wambier também pondera que há situações em que a nova redação deverá ser mais bem revista. Para ela, que já aponta seu pensamento no sentido de 
que a mudança redacional atinja as tutelas coletivas, vê que os interesses transindividuais não se esgotam de resultado pela simples redação do atual Código. A questão é mais emblemática, portanto. Inclusive, faz indagações e apontamentos sobre a necessidade de posicionamento da jurisprudência:

\begin{abstract}
A nova lei suprimiu o que havia no Código anterior (...). Sem dúvida, todavia, o dispositivo se aplica à coisa julgada coletiva (...). O NCPC não põe fim à polêmica doutrinária e jurisprudêncial acerca do art. 16 da Lei de Ação Civil Publica - e não poderia, mesmo porque o NCPC não trata do processo coletivo. A jurisprudência do STJ não se posicionou de forma definitiva sobre o tema (WAMBIER; CONCEIÇÃO; RIBEIRO; MELLO, 2016, p. 918).
\end{abstract}

Assim, parece importante a proposta de estudo, eis que a qualidade dos efeitos previstos nos dispositivos (revogado e atual) diz respeito à esfera material, ou seja, à esfera de interesses concretizados (SANTOS, 2017, p. 913).

De antemão, sobre o assunto, citam-se como referenciais teóricos, além dos já citados Eduardo Talamini, Tereza Arruda Alvim Wambier, Ernani Fidélis dos Santos e Antônio dos Passos Cabral, as lições de Cândido Rangel Dinamarco, quando faz importantes ressalvas sobre a figura do terceiro substituído (DINAMARCO; LOPES, 2017, p. 204); José Miguel Garcia Medina, quando faz apontamentos específicos sobre a necessidade de estudo do art. 506 do CPC/2015 em consonância com a tutela transindividual e as demandas coletivas (e ainda que não se concorde especificamente com as classificações do autor) (2016, p. 801); de Humberto Dalla Bernardina de Pinho, que consigna observações sobre a questão do direito intertemporal em relação aos referidos dispositivos (2016, p. 267).

Para o presente trabalho, que mesmo não possuindo uma posição conclusiva e definitiva sobre o tema, pretende-se demonstrar a urgência pelo efetivo estudo comparativo dos artigos 472 do CPC/73 e 506 do CPC/15 e suas implicações. É preciso o reconhecimento da correlação entre o eventual alcance do art. 506 do CPC/15 para com as ações coletivas, notadamente no que diz respeito aos limites subjetivos da coisa julgada. É o que se propõe.

\title{
3 AÇÕES COLETIVAS E O COMPARATIVO ENTRE OS ARTIGOS 472 DO CPC/73 E 506 DO CPC/2015.
}

O passar do tempo, os avanços tecnológicos e das relações jurídicas, demonstram a preocupação substancial quanto aos limites subjetivos da coisa julgada coletiva. Sabe-se que o artigo 506 do CPC alterou a redação do art. 472 do revogado CPC/73 (MEDINA, 2017, p. 
779). O destaque é na significativa mudança redacional e que talvez tenha de acrescer aquela preocupação, especialmente porque se acendem no ambiente jurídico as disposições acerca das ações coletivas e as compreensões acerca desta.

É notável que houve a exclusão da expressão "não beneficiando" terceiros, além da referência a que se fazia as causas relativas ao estado de pessoa, citados no processo e atuantes em litisconsórcio necessário, caso em que se produzia coisa julgada perante terceiro. Passou-se a uma redação objetiva, que talvez venha a realimentar a discussão doutrinária, como se propõe. O objetivo maior é entender se houve, de fato, manifesta alteração dogmática, principiológica e de aplicação.

O primeiro ponto que talvez tenha que ser de objeto de releitura esteja na interpretação de quem será atingido pela qualidade dos efeitos da coisa julgada, se somente as partes ou se os terceiros. Aparentemente, neste ponto não houve alteração redacional pelo CPC, contudo, pensa-se que a doutrina que se carreia nas discussões acerca da tutela coletiva - por sua significância - terão de reavaliar a questão.

Além disso, nesta perspectiva de reanálise, lembra-se que o CPC/73 previa que em que pese a sentença produzisse coisa julgada às partes do processo - quanto à sua eficácia em relação a terceiros -, permitia-se que a doutrina encontrasse percalços. Foram as discussões doutrinárias, especialmente difundidas pelas lições de Carnelutti e Liebman (SILVA, 2003, p. 95).

A antiga redação dizia que a coisa julgada não beneficiaria e nem prejudicaria terceiros. Porém, diante da reforma redacional, há que se discutir se houve um intento do legislador em aplicar a coisa julgada em favor dos terceiros beneficiados, tal como já se procedia ao tempo da lei revogada (in SILVEIRA, 2019, p. 4).

Mas a pergunta, que antes era feita ao tempo do CPC/73, repete-se: há, aqui, em favor dos terceiros beneficiados, a autoridade da coisa julgada em favor do terceiro beneficiado ou se beneficiam apenas da eficácia natural da sentença? As ações coletivas sofrem interferência pela mudança redacional?

No intuito de se chegar a estas respostas, talvez a doutrina precise fazer uma construção analítica, com base nos preceitos próprios das ações coletivas, do contexto jurídico em que ela se desenvolve (noção de ordem jurídica) e, especialmente, a partir dos institutos diretamente ligados, tal como o dos limites subjetivos da coisa julgada. 
Veja-se que a redação da última parte do art. 472 do CPC/73, já revogado, ao seu tempo dizia que nas causas relativas ao estado de pessoa, se houvessem sido citados no processo, em litisconsórcio necessário, todos os interessados, a sentença produziria coisa julgada em relação a terceiros. Ou seja, caso integrassem a relação processual (integrante do processo) em que a sentença foi dada, a coisa julgada a eles se faria (SILVA, 2003, p. 71). Esta previsão foi retirada, o que também levanta o debate acerca dos interesses transindividuais.

Numa linguagem primária, afigura-se numa análise ainda prévia que a corrente mais coerente seja a de que ainda a coisa julgada só se faz entre as partes entre as quais é dada, pois eiva-se de um antigo imperativo: a coisa julgada está somente para as partes do processo (DINAMARCO; LOPES, 2002, p. 317). Logo, se o terceiro interveio formalmente no processo, seu "status" se tornava equivalente ao da parte, portanto, sujeita a coisa julgada (sua imutabilidade), como discriminava a Lei processual. Mas isto só se pode ser afirmado após a melhor doutrina concluir pelos efeitos concretos da nova disposição legal.

Por isto tudo se pergunta: a alteração redacional, que se propôs pela exclusão de texto na parte final do art. 472 do $\mathrm{CPC} / 73$, em seu aspecto material foi ou não alterado? Esta é mais uma pergunta que se propõe diante de uma análise comparativa redacional dos dispositivos e cuja resposta está diretamente ligada aos interesses das demandas coletivas.

Atualmente, diante da exclusão da acenada parte final do art. 472 do CPC/73 (pelo art. 506 do (PC), talvez não tenha havido modificação substancial aos terceiros que intervierem formalmente no processo, pois, a princípio, estarão sob o mesmo status, de intervenientes e integrantes da relação processual levada à sentença. Pensa-se que o resultado da sentença relativamente a eles poderá permanecer o mesmo, eis que - de alguma forma colaboraram no resultado dela (WAMBIER; MEDINA, 2003, p. 20).

Mas, reitera-se: a doutrina precisa se preocupar com estas preposições, afinal, a tutela coletiva é uma conquista jurídica e de alto reflexo se analisa como um instituto. Ao se remontar a discussão acerca da exclusão da parte final do dispositivo revogado, tratar-se-á imediatamente dos efeitos da coisa julgada, seus limites e seu grau de interferência nas demandas transindividuais/coletivas. Por conseguinte, remonta-se a discussão ainda não superada acerca dos terceiros (à relação jurídica travada pelas partes) e se são alcançados pela coisa julgada (SILVA, 2003, p. 102). 
Não apenas isto: se há - e isto precisa ser urgentemente tratado pela doutrina - o intento do legislador em beneficiar os terceiros não intervenientes na relação processual findada por sentença (por meio da exclusão redacional do art. 506 do CPC/15), devendo determinar-se se há autoridade da coisa julgada para tais terceiros ou lhes cabe apenas uma eficácia natural da sentença. Para alguns há coisa julgada para terceiros, no sentido de que "o art. 506 acolheu a possibilidade de formação da coisa julgada 'secundum tenorem rationis', cuja introdução no direito brasileiro era já requerida pela doutrina. [...] pode aproveitar a coisa julgada formada inter alios" (MARINONI; ARENHART, 2015, p. 629), contudo, para outros este posicionamento não é verdadeiro (DINAMARCO, 2017, p. 202).

O fato é: analisando-se o art. 506 do nCPC, no que diz respeito à exclusão da parte final do antigo dispositivo, a doutrina deverá se definir por uma ou outra posição.

Vale dizer, o dispositivo deve ser interpretado no sentido de permitir a extensão da coisa julgada? E neste caso, abrangeria também o conceito da coisa julgada coletiva ou limitado apenas à coisa julgada individual?

\section{AUTORIDADE DA COISA JULGADA E SUA EFICÁCIA NATURAL.}

Os limites objetivos e subjetivos da coisa julgada ganharam alento doutrinário com as disposições do art. 472 do CPC/73, atualmente substituído pelo art. 506 do CPC. No entanto, para que houvesse substancial leitura, precedia-se da compreensão de coisa julgada e de eficácia natural da sentença.

Com a alteração redacional dos textos, da qual se pretende dar atenção ao intérprete e aplicador da norma, a leitura do art. 506 do CPC parece adentrar, novamente, no campo próprio dos limites subjetivos da coisa julgada, o que pode interferir diretamente nos casos a serem resolvidos pela tutela coletiva. Portanto, a prévia releitura acerca da autoridade da coisa julgada e da eficácia natural da sentença, servem de direção para a futura interpretação da norma diante de uma tutela coletiva, conforme o caso.

Neste passo, recorda-se que a imutabilidade de uma decisão até a proposta doutrinária de Enrico Tullio Liebman era vista por muitos como um mero efeito da sentença. Seus estudos, que chegaram ao Brasil, permitiram evitar alguns equívocos que se estendiam pela história das ciências jurídicas. Ao tratar da sentença, da coisa julgada e seus efeitos, redefiniu-os em duas categorias autônomas e independentes, o da eficácia natural da sentença 
e a autoridade da coisa julgada. A proposta, diante do caráter da sentença, partia de entender sua eficácia não mais como sinônimo de coisa julgada, pois não se atingia partes e terceiros de igual modo. Em que pese a sentença produza efeitos erga omnes, ou seja, para todos, isto é mera decorrência de sua eficácia natural, contudo, a autoridade da coisa julgada só estaria para aqueles que fossem considerados partes do processo, pois estes foram participantes da formação da sentença (inter partes). E se a eficácia atinge a todos, logo, aos terceiros são estendidos os seus efeitos (BUENO, 2011, p. 32). O jurista ainda justificava sua sistematização:

II) A eficácia da sentença nos limites de seu objeto, não sofre nenhum limitação subjetiva; vale em face de todos. III) A autoridade da coisa julgada não é efeito ulterior e diverso da sentença, mas uma qualidade dos seus efeitos e a todos os seus efeitos referente, isto é precisamente a sua imutabilidade. Ela está limitada subjetivamente às partes do processo. IV) Consequentemente, todos os terceiros estão sujeitos à eficácia da sentença, não, porém, a autoridade da coisa julgada; a sentença, nos limites de seu objeto, é sempre oponível a eles, que lhes podem repelir os efeitos, demonstrando a sua injustiça, uma vez que tenham interesse jurídico na demonstração (LIEBMAN, 1984, p. 21).

Foi um marco, mas que evidentemente foi objeto de debate doutrinário. Como protagonista de uma das teorias contrapostas, consideram-se as lições de Francesco Canelutti, também jurista italiano. Para ele, Liebman não poderia apontar a imutabilidade da sentença às partes e sem que os terceiros não pudessem se atingidos por tal qualidade da sentença. $O$ problema estaria exatamente nos limites subjetivos, de modo que os terceiros eram, sim, atingidos pela autoridade da sentença. Assim, classificava os efeitos da sentença quanto à sua eficácia direta e reflexa, de modo que nesta última estaria a referida extensão a terceiros (CARNELUTTI in BUENO, 2011, p. 34-35)

Fazendo-se um paralelo entre as correntes, percebe-se uma atenção especial de Liebman, da qual entende adequada. Desde o Direito Romano, passando especialmente pela idade média, chegando às concepções de Giuseppe Chiovenda e Carnelutti, o instituto da coisa julgada (antes entendida como "presunção de verdade") era visto, em linhas gerais, como "efeito da sentença". Entretanto, a proposta liebmaniana não dizia (não diz) respeito aos efeitos em si, mas sim a "qualidade dos efeitos da sentença", mais precisamente como a qualidade de imutabilidade de tais efeitos. Para ele há aqui uma qualidade, "mais intensa e mais profunda, que reveste o ato também em seu conteúdo e torna imutáveis, além do ato em 
sua existência formal, os efeitos, quaisquer que sejam, do próprio ato" (apud ANTUNES; BELLINETTI, 2010, p. 7368).

Basicamente, pelo esclarecimento de Liebman, por conta da imutabilidade alcançar as partes (noção de autoridade da coisa julgada), os terceiros simplesmente participam, tal como as partes, da eficácia natural da sentença, mas podem se opor aos efeitos da sentença demonstrando a "injustiça da decisão" (MACEDO, 2017, p. 119). A injustiça da decisão carrega consigo exatamente a noção de que aos terceiros não lhes coube formar a decisão, tal como as partes da relação processual.

Assim, talvez seja justo entender que na eventual análise equiparada dos artigos 472 do CPC/73 e 506 do CPC/15, por submergirem no campo das ações coletivas (que atualmente se intensificam no cenário jurídico-institucional), preceda-se previamente das compreensões e orientações técnicas fundamentais acerca da coisa julgada e de sua eficácia natural.

\section{OS LIMITES OBJETIVOS E SUBJETIVOS DA COISA JULGADA NAS AÇÕES COLETIVAS ATÉ O CPC/73.}

Mesmo após a reforma, os limites objetivos da coisa julgada, seja nas ações individuais, quanto coletivas, parecem não encontrarem confrontos ou similares percalços na doutrina. Diz-se que a sentença dirá tais limites conforme o posto em seu dispositivo (em regra), ou seja, aquilo que decidido definitivamente na parte dispositiva, entenda-se: onde não se há o alcance do fundamento sentencial (causa de decidir; ainda que conduzirem à construção da parte dispositiva), apontará os alcances de decidir. É o resultado emitido pelo órgão jurisdicional a respeito do pedido na formulação da ação (THEODORO JUNIOR, 1997, p. 66 e 72). Dai se entender a importância dos limites objetivos da coisa julgada para se compreender que, de fato, a sentença tem força de lei (nos limites das questões decididas art. 503, caput do nCPC) e nela se amolda a garantia constitucional da coisa julgada - art. $5^{\circ}$, XXXVI da CF - (LUCCA, 2016, p. 3).

As contraposições começam a se relativizar quando o tema é coisa julgada, especialmente aos limites subjetivos da coisa julgada nas ações coletivas. Basicamente, o entendimento prevalecente é de que "os limites subjetivos da coisa julgada dizem respeito, em geral - em uma simplificação de termos -, a "quem" restaria atingido por tal qualidade dos efeitos da sentença" (ANTUNES; BELLINETTI, 2010, p. 7370). 
Há décadas o tema é discutido. Por exemplo, no Código de Processo Civil de 1973, o art. 472 descrevia que a sentença fazia coisa julgada às partes entre as quais era dada, não beneficiando, nem prejudicando terceiros, mas nas causas relativas ao estado de pessoa, se houvessem sido citados no processo, em litisconsórcio necessário, todos os interessados, a sentença produzia coisa julgada em relação a terceiros (Lei n. ${ }^{\circ}$ 5.869, de 11 de janeiro de 1973 $-\mathrm{CPC} / 73)$.

Parecia claro o intento do legislador da época, no sentido de que a autoridade da coisa julgada estava para as partes integrantes do processo, pois da leitura que se expunha do dispositivo, tanto na primeira, quanto na segunda parte, de alguma forma os atingidos pela coisa julgada participaram do processo. Contudo, passou-se a um debate, relacionado aos efeitos que poderiam se estender (noção de eficácia natural da sentença, como visto no item anterior) aos terceiros (SILVA, 2003, p. 86).

Neste tempo, alguns afirmavam que em que pese a descrição do Código Processual prescrever que a coisa julgada não atingiria terceiros, seria inegável tal extensão, pois havia situações jurídicas em que o terceiro, no plano de direito material, encontrava-se "na mesma posição jurídica de um dos demandantes ou então é um titular de relação conexa com a res de qua agitur" (TUCCI, 2006, p. 209) ou na hipótese "inter alios, quando são titulares de um direito incompatível com o objeto da decisão", ainda que tal fenômeno a terceiro fosse “excepcional” (TUCCI, 2006, p. 208).

Noutra linha, manteve-se uma corrente preservacionista: a de que a coisa julgada atingiria somente aqueles que participaram do processo, pois a coisa julgada é um instituto decorrente do contraditório e do devido processo legal (THEODORO JUNIOR, 1997, p. 14) e, sobretudo, da segurança jurídica (ANTUNES; BELLINETTI, 2006, p. 7368). Caminhava no seguinte sentido:

\footnotetext{
A contrário senso, o terceiro que, em virtude da eficácia natural, é beneficiado por uma sentença, prolatada em uma relação jurídica processual da qual não tenha participado, também, de qualquer forma, resta prejudicado no que ser refere à possibilidade de questionamento judicial de tal decisão, não porque seja limitado pela autoridade da coisa julgada, propriamente dita, mas porque não tem interesse de agir, para tanto, e é, desta forma, carecedor de ação (ANTUNES; BELLINETTI, 2006. p. 7375).
}

O fato é que o CPC inaugura um novo tempo normativo e as ações coletivas e a tutela transindividual aguardam respaldo doutrinário suficiente para se aferir se houve ou não 
uma ruptura substancial para com o dispositivo do CPC/73. Ainda que o artigo art. 506 do CPC rubrique que a sentença faz coisa julgada às partes entre as quais é dada, não prejudicando terceiros, é preciso se verificar a pertinência da afirmativa de que a coisa julgada não alcançaria terceiros, especificamente no que diz respeito a seus efeitos (DELLORE, 2018, p. 7), especialmente na seara coletiva.

\section{OUTRAS QUESTÕES CORRESPONDENTES À PROPOSTA DE REANALISE COMPARATIVA}

Neste ponto, com a preocupação de que haja um silêncio doutrinário em relação à alteração redacional entre os artigos 472 do CPC/73 e o art. 506 do nCPC, faz-se outros apontamentos substanciais e de importância já tratados pela doutrina e pela jurisprudência acerca do tema.

\subsection{Do transporte in utilibus da coisa julgada coletiva em comparativo ao art. 506 do CPC/15.}

Faz-se uma análise analógica quanto ao transporte in utilibus da coisa julgada coletiva, pois se imagina (a título sugestivo) que a análise deste instituto pode colaborar com a doutrina no que diz respeito à compreensão, ainda que analógica, do comparativo entre artigos 472 do CPC/73 e o art. 506 do CPC/15.

O transporte in utilibus, que pode assim ser definido como a possibilidade de aproveitamento da coisa julgada coletiva para em favor da esfera individual (WATANABE, 2008, p.304), ganhou rótulo normativo clássico pelo art. $103 \S 3^{\circ}$ do Código de Defesa do

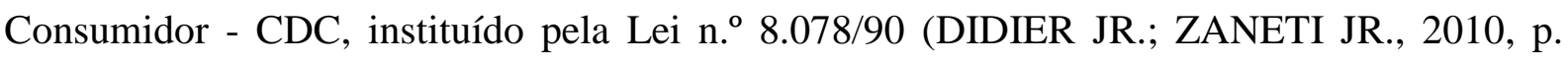
370).

Nessa esteira, o diferencial do processo coletivo é a viabilidade do transporte in utilibus da coisa julgada coletiva para a esfera individual, consectário do princípio do máximo benefício na tutela jurisdicional coletiva (art. 103, $\S \S 3^{\circ}$ e $4^{\circ}$, do CDC). Com isso, os efeitos da coisa julgada devem ser projetados para além da conclusão da decisão. $\mathrm{O}$ transporte in utilibus sonda-se com base na teoria da transcendência dos motivos determinantes, radicado do controle de constitucionalidade, em que a ratio decidendi (ou tragende Gründe) passa a ter força obrigatória relativizando o limite objetivo da coisa julgada. Nessa linha, há o aproveitamento da cognição 
delineada no processo coletivo para permitir que o particular sequer tenha que propor seu pedido individualmente, permitindo partir diretamente da liquidação (imprópria). Ou seja, encurtará a discussão da existência da obrigação (an debeatur), de quem é obrigado (quis debeat) e o que é devido (quid debeatur) (LESSA, 2013, p. 100).

Há preocupação do transporte não “a quem” será transportado, mas sim “o que” será objeto de transporte (LUCCA, 2016. p. 2-3). Nesta linha, ao que se aparenta, o $\S 3^{\circ}$ do art. 103 do CDC reconhece que a coisa julgada perante terceiros não ocorre em seu prejuízo, pois não são parte integrante da relação processual. Além disso, note-se que no $\S 2^{\circ}$ do dispositivo, estabelece o legislador que na hipótese de terceiros interessados em face de um julgamento de improcedência em ação coletiva não serão prejudicados, justamente por não terem intervindo no processo como litisconsortes. Em outros termos, ao menos do que se previamente analisa, os limites subjetivos da coisa julgada os alcançariam caso fizessem parte integrante da relação processual, oportunidade em que a coisa julgada se produziria normalmente.

Como já visto, Antônio dos Passos Cabral descreve expressamente que o art. 506 do CPC/15 se trata exatamente de transporte in utilibus em favor de terceiro (in TALAMINI, p. 811-812), mas veja-se: não mais no plano especial normativo, como é o caso do CDC, mas junto à processual regra geral.

Deste modo, aparentemente o legislador pretendeu tratar do transporte in utilibus da coisa julgada, especialmente coletiva, o que aquece ainda mais a discussão acerca do art. 472 do CPC/73 em comparação com o artigo 506 do CPC. Ainda que se tenha por quase definido para a doutrina que a autoridade de coisa julgada se fará apenas para as partes do processo, a qualidade dos efeitos será de importante necessidade de revisão, especialmente diante do eventual transporte que diz respeito ao conteúdo da regra (In SILVA, 2003, p. 80).

\subsection{Do Enunciado n. 36 da I Jornada de Direito Processual Civil do Conselho da Justiça Federal em comparativo ao art. 506 do CPC/15.}

Formada em Brasília-DF, em 24 e 25 de agosto de 2017, a I Jornada de Direito Processual Civil do Conselho da Justiça Federal, aprovou o Enunciado n. ${ }^{\circ}$ 36, que trata especificamente dos benefícios da coisa julgada, especialmente no que diz respeito à aplicação do art. 506 do Código de Processo Civil no âmbito da Justiça Federal. É a redação: 
Enunciado n. ${ }^{\circ}$ 36: $\mathrm{O}$ disposto no art. 506 do CPC não permite que se incluam, dentre os beneficiados pela coisa julgada, litigantes de outras demandas em que se discuta a mesma tese jurídica (CJF, 2017, p. 1).

Em que pese a ausência de força de lei, há, pelo Conselho da Justiça Federal, a criação de um indicativo para as ulteriores decisões, um referencial mínimo e que dá suporte ao enfrentamento da questão relacionada à autoridade e eficácia da coisa julgada, pois na hipótese de um terceiro beneficiário estar, ao mesmo tempo, litigando, ou seja, integrando uma outra relação processual que diga respeito à mesma relação de direito material, não poderá invocar a condição de terceiro beneficiário.

\subsection{Da coisa julgada e dos princípios fundamentais ao Direito Processual Civil}

A segurança jurídica configura valor imprescindível à comunhão social, não sendo por outra razão que a coisa julgada, destinada à sua concretização, encontra-se prevista no art. 5, inciso XXXVI da Constituição Federal (MACEDO, 2017, p. 42). É um prisma a ser consagrado pela legislação infraconstitucional e pelo aplicador do Direito.

A grande motivação de tanto o antigo, quando ao atual legislador processual civil se ter garantido a coisa julgada à somente as partes do processo e a qualidade de seus efeitos extensível a todos, incluindo terceiros, parte de uma cautela, portanto, de uma segurança jurídica fundamental. Este é um princípio assecuratório da coisa julgada. Assim, todo o conflito de interesses, num determinado momento, deve encerrar-se, em regra, atribuindo-se, a quem assim decidido, o bem da vida perquirido, noção escorreita da adoção do princípio da segurança jurídica (MACEDO, 2017, p. 42).

Esta segurança das partes advém de uma noção primária, a de garantia de que esta decisão seja proferida com a efetiva participação das partes, por meio do contraditório e da ampla defesa, e o evitar de ingerências arbitrárias do Estado - leia-se contrária ou não prevista em lei -, por meio de decisões injustiças, portanto, sem o respeito ao devido processo legal (DALSENTER, 2007, p. 2265).

Neste ponto, concorda-se com Tucci, no sentido de que se deve assegurar a todos um devido processo legal que assegure a materialidade do acesso à justiça, perante um juiz natural constituído e onde as partes possam exercer a garantia do contraditório e da ampla 
defesa, com a devida paridade de armas, por meio de um processo publicístico e com decisões juridicamente motivadas, tudo com razoabilidade de tempo (TUCCI, 2006, p. 105).

Por isso, ao tratar do princípio do contraditório, a doutrina pauta seu diálogo diretamente com as exigências da coisa julgada. Desta deriva, portanto, o entendimento de que somente depois de uma regular citação, depois de ouvidas ambas as partes, a sentença afetará somente estes. Estas três consequências decorrem exatamente do princípio do contraditório (THEODORO JUNIOR, 1997, p. 14).

Portanto, a segurança jurídica é um ponto fundamental para se aferir sobre a autoridade e os efeitos naturais da coisa julgada nas ações coletivas, sendo a garantia da segurança jurídica, ainda que não garanta juízos de certeza, quanto àquilo que for realmente justo (certeza imperiosa), traz consigo a paz social e controle das relações. Assim, a certeza das relações e o mínimo a que se está submetido à coisa julgada, deve partir da efetivação da segurança jurídica (THEODORO JUNIOR, 1997, p. 59-60).

Esta noção é imperiosa para se compreender a sentença, que fará coisa julgada e produzirá efeitos, como um ato comunicativo, onde a sociedade espera que pelo julgamento se obtenha o controle institucional relacionado próprio ao Estado e ao processo (ANTUNES; BELLINETTI, 2010, p. 7367). Veja-se um reclamo social, e não apenas das partes, produzindo-se, em linhas gerais uma noção de inter-relação humana e jurídica (SOTO, 2001, p. 25). Portanto, e assim, os estudos específicos do art. 472 do CPC/73 em comparativo com o art. 506 do CPC/15 são imperativos.

\section{CONCLUSÃO}

Conclui-se que a alteração significativa do texto redacional entre os artigos 472 do CPC/73 e 506 do CPC/15 influi na interpretação da coisa julgada, a qualidade de seus efeitos, inclusive na tutela dos interesses transindividuais, sobretudo nas ações coletivas.

Do que se percebe, ainda há um relativo silêncio da doutrina em relação à referida alteração redacional.

Quando o jurista nota a exclusão das expressões "beneficia" terceiros ou quando se percebe que o art. 506 do CPC deixou a antiga previsão formal de que nas causas relativas ao estado de pessoa, se houvessem sido citados no processo, em litisconsórcio necessário, todos os interessados, a sentença produzia coisa julgada em relação a terceiros, não basta uma leitura simples - apenas interpretativa do que o legislador quis dizer ou não - mas 
aprofundada e sistemática, isto porque uma simples alteração redacional ou uma interpretação equivocada pode alterar toda, ou boa parte, de uma estrutura de um instituto jurídico.

Do que se denotou, a doutrina já começa a dar indicativos da presença do transporte in utilibus no ordenamento geral; começa a rediscutir os limites previstos no art. 506 do CPC/15, para uns influindo nos limites objetivos e, para outros, nos limites subjetivos; outros, mesmo dando suas opiniões, já se arriscam dizer que é preciso uma análise mais aprimorada antes de se construir uma interpretação definitiva.

Do que se aparenta, os limites subjetivos da coisa julgada, sua autoridade e efeitos, inclusive no atinente aos interesses transindividuais e as ações coletivas, poderão ser atingidos pela alteração redacional, circunstância que demanda desenvolvimento de novos e mais aprofundados estudos.

Portanto, propondo-se um urgente debate, percebe-se a importância de que os benefícios da coisa julgada a terceiros deva ser interpretada e deliberada conforme seus preceitos elementares, seus limites (especialmente os subjetivos), dentro de uma ordem principiológica e em conformidade com todo o ordenamento, sob pena de se inferir num campo de desestruturação de institutos jurídicos já (ou quase) sedimentados e/ou se proferir decisões que contrariem a efetiva justiça. Mas isto só será possível com a participação efetiva dos juristas, notadamente pela doutrina.

\section{REFERÊNCIAS BIBLIOGRÁFICAS}

ANTUNES, Thiago Caversan; BELLINETTI, Luiz Fernando. Os limites subjetivos da coisa julgada nas ações Coletivas. In: Vladmir Oliveira da Silveira. (Org.). XIX Encontro Nacional do Congresso Nacional do Conselho Nacional de Pesquisa e Pós-Graduação em Direito no Brasil. 1. ed. Florianópolis: Fundação Boiteux, 2010, p. 7364-7378. BUENO, Cássio Scarpinella. Coisa julgada coletiva. São Paulo: Saraiva, 2011. BRASIL. Conselho da Justiça Federal. I Jornada de Direito Processual Civil. Disponível: <https://www.cjf.jus.br/cjf/noticias/2017/setembro/copy_of_Enunciadosaprovadosvfpub.pdf> . Acesso em: 12 mar. 2019.

DALSENTER, Thamis Ávila. Função social da coisa julgada: por uma reorientação hermenêutica no campo do direito processual civil. XVI Congresso Nacional do Conselho 
Nacional de Pesquisa e Pós-Graduação em Direito no Brasil. Belo Horizonte: Conpedi, 2007. p. 2256-2275.

DELLORE, Luiz. Quem é atingido pela coisa julgada no NCPC? Divergências acerca dos limites subjetivos da coisa julgada. Disponível em: <https://www.jota.info/opiniao-eanalise/colunas/novo-cpc/quem-e-atingido-pela-coisa-julgada-no-ncpc-10072018\#_ftnref3>. Acesso em: 8 mar. 2019.

DIDIER JR., Fredie; ZANETI JR., Hermes. Curso de Direito Processual Civil: processo coletivo, v. 4. 5. ed. Salvador: Juspodivm, 2010.

DINAMARCO, Cândido Rangel; LOPES, Bruno Vasconcelos Carrilho. Teoria geral do novo processo civil. 2. ed. Revista atualizada. São Paulo: Malheiros, 2017.

Fundamentos do Processo Civil Moderno. 2 ed. São Paulo: RT, 1987 in

ANTUNES, Thiago Caversan; BELLINETTI, Luiz Fernando. Os limites subjetivos da coisa julgada nas ações Coletivas. In: Vladmir Oliveira da Silveira. (Org.). XIX Encontro Nacional do Congresso Nacional do Conselho Nacional de Pesquisa e Pós-Graduação em Direito no Brasil. 1 ed. Florianópolis: Fundação Boiteux, 2010, p. 7364-7378.

LESSA, G. C. Extensão subjetiva e objetiva da coisa julgada coletiva: possibilidade de liquidação dos danos particulares a partir de pronunciamento coletivo (transporte in utilibus).

Revista Luso-Brasileira de Direito do Consumo, v. III, n. 9. mar. 2013.

LIEBMAN, Enrico Tullio. Eficácia e autoridade sentença e outros escritos sobre a coisa julgada (com aditamentos relativos ao direito brasileiro). 3. ed. Rio de Janeiro: Forense, 1984. In: BUENO, Cássio Scarpinella. Coisa julgada coletiva. São Paulo: Saraiva, 2011.

LUCCA, Rodrigo Ramina de. Os limites objetivos da coisa julgada no novo código de processo civil. Revista de Processo, v. 252/2016, fev. 2016, DTR, 2016/207. Disponível em: $<$ https://edisciplinas.usp.br/pluginfile.php/2765741/mod_resource/content/0/Os\%20limites\%2 0objetivos $\% 20 \mathrm{da} \% 20$ coisa\%20julgada\%20no\%20novo\%20CPC\%20-

\%20Rodrigo\%20Ramina.pdf >. Acesso em: 5 mar. 2019.

MACEDO, Elaine Harzheim; CUNHA, Marcelo Garcia da. Coisa Julgada Transnacional: considerações sobre a possibilidade de sua automática projeção no Brasil. In: Amélia do Carmo Sampaio Rossi; Florisbal de Souza Del Olmo. (Org.). Direito Internacional II. 1. ed. Florianópolis: CONPEDI, 2017, v. 1, p. 40-57.

MARINONI, Luiz Guilherme; ARENHART, Sérgio Cruz. Curso de processo civil: Processo de conhecimento. v. 2. São Paulo: Editora RT, 2015. 
MEDINA, José Miguel Garcia. Novo Código de Processo Civil Comentado. 3. ed. São Paulo: Revista dos Tribunais, 2015.

Direito processual civil moderno. 2. ed. São Paulo: Revista dos Tribunais,

2015.

RODRIGUES, Marcelo Abelha. Manual de Direito Processual Civil. 6. ed. Rio de Janeiro: Forense, 2016.

SANTOS, Ernane Fidélis dos. Manual de Direito Processual Civil. Processo de conhecimento. 16. ed. São Paulo: Saraiva, 2017.

SILVA, Ovidio Araujo Baptista. Sentença e Coisa Julgada: ensaios e pareceres. 4. ed. Rio de Janeiro: Forense, 2003.

SILVEIRA, Artur Barbosa da. Da sentença e da coisa julgada: principais inovações do atual Código de Processo Civil. Disponível em:

<www.ambitojuridico.com.br/site/?n_link=revista_artigos_leitura\&artigo_id=20264\&revista_ caderno=21>. Acesso em: 12 mar. 2019.

SOTO, Erica Antonia Bianco de. Sentença civil: Perspectiva pragmática. Campo Grande: UCDB, 2001.

TALAMINI, Eduardo; WAMBIER, Luiz Rodrigues. Curso avançado de Processo Civil. Cognição jurisdicional (processo de conhecimento e tutela provisória). v. 2. 16. ed. São Paulo: Revista dos Tribunais, 2016.

THEODORO JÚNIOR, Humberto. Sentença: Direito Processual Civil ao vivo. 2. ed. atual. Rio de Janeiro: Aide, 1997.

TUCCI, José Rogério Cruz e. Limites subjetivos da eficácia da sentença e da coisa julgada civil. São Paulo: Revista dos Tribunais, 2006.

WAMBIER, Teresa Arruda Alvim. Novo CPC urgente. Guia esquemático para conhecer o novo CPC. São Paulo: Revista dos tribunais, 2016.

; MEDINA, José Miguel Garcia. O dogma da coisa julgada: Hipóteses de relativização. São Paulo: Revista dos Tribunais, 2003. ; CONCEIÇÃO, Maria Lúcia Lins; RIBEIRO, Leonardo Ferres da Silva; MELLO, Rogerio Licastro Torres de. Primeiros comentários ao novo código de processo civil: Artigo por artigo. São Paulo: Revista dos Tribunais, 2016.

WATANABE, Kazuo. XIII World Congress of Procedural Law. In: GRINOVER, Ada Pellegrini; WATANABE, Kazuo; MULLENIX, Linda. Os processos coletivos nos países da 
civil law e common law: uma análise de direito comparado. São Paulo: Revista dos Tribunais, 2008. 